\title{
Screening of Syphilis in Abroad Job Seeking Healthy Males
}

\author{
Shrestha $B^{1}$ \\ 'Department of Microbiology, Tribhuvan University Tri-Chandra Campus
}

\begin{abstract}
This study was carried out to find out the prevalence of syphilis is healthy male populations. Test for Syphilis is mandatory for those who apply for overseas employment, especially in Middle East countries. From randomly selected Nepalese male population (16-50 years) seeking jobs abroad, 2585 blood samples were collected and tested by nontreponemal test, the Rapid Plasma Reagin test and by treponemal test, the Treponema pallidum haemagglutination test. Confirmed cases of syphilis were $22(0.85 \%)$. No association of syphilis with any age groups $\left(X^{2}=6.6465, P>0.05\right)$ and development regions were observed $\left(X^{2}=1.8782, P>0.05\right)$. Syphilis occurrence was almost equal in terai $(0.94 \%)$ and hilly region $(0.9 \%)$ and was none in mountainous region showing no association $\left(X^{2}=1.5334\right.$, $\mathrm{P}>0.05)$. In eastern development region, all the cases were from terai region showing significantly greater occurrence of syphilis in terai region $\left(\mathrm{X}^{2}=4.334, \mathrm{P}<0.05\right)$. In the contrary, all the cases of syphilis in mid-western development region were from hilly region, however this finding was not statistically significant $\left(X^{2}=0.5497, P>0.05\right)$. Asymptomatic stage of syphilis may lead to tertiary syphilis; hence, People should be educated about the disease; they should be screened and treated when required.
\end{abstract}

Key Words: asymptomatic, latent stage, rapid plasma reagin, syphilis, screening

\section{INTRODUCTION}

Painlessness and hidden sites make primary chancre unnoticed and social stigma makes screening studies dependable on serological screening tests. By serological tests People are diagnosed in latent stage, which persist for the remainder of life or may give rise to granulomatous lesions, cardiovascular and neurological disorders. ${ }^{1,2}$ Serological diagnosis depends on tests consisting of non-treponemal and treponemal tests, which are complimentary and provide excellent screening at all stages. ${ }^{3}$
Ascending and descending syphilis incidence has been observed in USA, UK, Wales and Scotland; and the surge observed in incidence was due to HIV infection..$^{4,5}$ In sexually transmitted disease (STD) clinic in Calcutta, $3.88 \%$ of the subjects were reactive for VDRL test and $16.6 \%$ of male up to 30 years were reactive. ${ }^{6}$ whereas $2.4 \%$ of the women attending antenatal clinic were found VDRL positive in Maharastra and $1.4 \%$ in Kerala. ${ }^{7}$ Present study was aimed to screening healthy Nepalese male population as the asymptomatic cases act as reservoir and spread the disease unknowingly.

\footnotetext{
Correspondence:

Mrs. Bidya Shrestha

Department of Microbiology

Tribhuvan University Tri-Chandra Campus

Kathmandu, Nepal.

Phone:+977-9841350850

Email: bshrestha@enet.com.np
} 
Shrestha. Screening of Syphilis in Abroad Job Seeking Healthy Males

\section{MATERIAL AND METHODS}

The is a multicentre, cross-sectional study of healthy males from different development regions of Nepal who required medical check-up for employment abroad. They did not exhibit any signs and symptoms of syphilis. Most of them were from rural areas and were lacking knowledge of syphilis and its consequences. Consent for test from all the subjects was taken and their privacy was assured.

Blood samples of 2585 healthy randomly selected Nepalese male populations within the age range of 16-50 were collected during July to September 1999 in a government registered medical center. Sera were separated and tested on the same day to detect reaginic antibody by using non-treponemal cardiolipin antigen test, the RPR test. All the cases reactive in RPR test were tested further with specific treponemal test, the TPHA test for confirmation of the presence of specific antibody against Treponema pallidum antigen. The kits used were Teco, USA for rapid plasma reagin (RPR) and Immunotrep TPHA, Omega Diagnostica, UK for Treponema pallidum haemagglutination TPHA. The standard methodology prescribed by the manufacturer was exactly followed. Titre of RPR test was also obtained.

The cases positive in both RPR and TPHA tests were reported as confirmed cases of syphilis. Those cases with positive reaction with RPR (neat or titre 2) and negative in TPHA were tested after six months; and there was no increase in the titre and TPHA remained negative, hence were identified as biological false positives. Confirmed cases of syphilis were referred to the physician for treatment. The data was analyzed statistically by using chi square test.

\section{RESULT}

Out of 2585 subjects tested, 25 were reactive in RPR test whereas TPHA test was positive only in 22 subjects. That is, three subjects were positive in RPR and negative in TPHA test were identified as biological false positive cases. Twenty-two were confirmed cases of syphilis, making the prevalence of syphilis in target healthy male population of $0.85 \%$.

The occurrence of syphilis was not consistent in all age groups rather it was observed greatest $1.7 \%$ in $31-35$ age group followed by $41-45,26-30,36-40$ and 21 25 age groups with respective prevalence of $1.17 \%$, $1.01 \%, 0.83 \%$, and $0.54 \%$. In two age groups $16-20$ and 46-50 no cases of syphilis was observed (Table 1). Two age groups 41- 45 and 46-50 were excluded from the statistical calculation due to comparatively small sample size ( 85 and 24 respectively). No association of age group with syphilis was observed $\left(X^{2}=6.6465\right.$, $\mathrm{P}>0.05)$.
Table1. Occurrence of syphilis in different age groups

\begin{tabular}{lll}
\hline Age group & No. Tested & Syphilis (\%) \\
\hline $16-20$ & 220 & $0(0 \%)$ \\
$21-25$ & 915 & $5(0.54 \%)$ \\
$26-30$ & 690 & $7(1.01 \%)$ \\
$31-35$ & 412 & $7(1.7 \%)$ \\
$36-40$ & 239 & $2(0.83 \%)$ \\
$41-45$ & $85 *$ & $1(1.17 \%)$ \\
$46-50$ & $24 *$ & $0(0 \%)$ \\
Total & 2585 & $22(0.85 \%)$ \\
\hline
\end{tabular}

*Not included in statistical calculation due to comparatively small sample size in this age group

Table 2. Distribution of syphilis in different development regions

\begin{tabular}{lll}
\hline Development region & No. Tested & Syphilis (\%) \\
\hline Eastern & 1036 & $6(0.58)$ \\
Central & 550 & $6(1.1 \%)$ \\
Western & 851 & $8(0.94 \%)$ \\
Mid-Western & 144 & $2(1.39 \%)$ \\
Far-Western & $4 *$ & $0(0 \%)$ \\
\hline
\end{tabular}

* Not included in statistical calculation due to comparatively small sample size.

Table 3. Prevalence of syphilis in different regions

\begin{tabular}{lll}
\hline Region & Total No. & Syphilis (\%) \\
\hline Terai & 1065 & $10(0.94 \%)$ \\
Hilly & 1351 & $12(0.9 \%)$ \\
Mountainous & 165 & $0(0 \%)$ \\
\hline
\end{tabular}

The occurrence of syphilis was highest $(1.39 \%)$ in mid-western development region and least $(0.58 \%)$ in eastern development region (Table 2). However, no significant difference in occurrence of syphilis in different development regions of the country was observed $\left(X^{2}\right.$ $=1.8782, \mathrm{P}>0.05)$. The occurrence of syphilis was almost equal in terai $(0.94 \%)$ and hilly region $(0.9 \%)$ and no cases were detected in mountainous region $(0 \%)$, the least populated area from where the sample size was not as big as in terai and hilly regions (Table $3)$. No significant association of syphilis with regions was observed $\left(X^{2}=1.5334, P>0.05\right)$.

All the cases of syphilis in Eastern development region were from terai region and none were from the hilly and mountainous region (Table 4). This finding of greater occurrence of syphilis with terai region of Eastern 
Shrestha. Screening of Syphilis in Abroad Job Seeking Healthy Males

Table 4. Prevalence of Syphilis in different regions of various development regions

\begin{tabular}{|c|c|c|c|c|c|c|c|c|c|}
\hline \multirow[b]{2}{*}{ Region } & \multicolumn{2}{|c|}{ Eastern } & \multicolumn{2}{|c|}{ Central } & \multicolumn{2}{|c|}{ Western } & \multicolumn{2}{|c|}{ Mid western } & \multirow[b]{2}{*}{ Total } \\
\hline & No. & Positive & No. & Positive & No. & Positive & No. & Positive & \\
\hline Terai & 542 & $6(1.10 \%)$ & 348 & $3(0.86 \%)$ & 136 & $1(0.73 \%)$ & 39 & - & 1065 \\
\hline Hilly & 390 & - & 185 & $3(1.62 \%)$ & 671 & $7(1.04 \%)$ & 105 & $2(1.9 \%)$ & 1351 \\
\hline Mount & 104 & - & 17 & - & 44 & - & - & - & 165 \\
\hline Total & 1036 & $6(0.58 \%)$ & 550 & $6(1.09 \%)$ & 851 & $8(0.94 \%)$ & 144 & $2(1.39 \%)$ & 2581 \\
\hline
\end{tabular}

development region was significant $\left(X^{2}=4.334\right.$, $\mathrm{P}<0.05)$. Consequently, all the cases of syphilis in Mid-Western development region were from hilly region and none were from terai, however this finding was not significant $\left(X^{2}=0.5497, P>0.05\right)$. In Central and Western development regions, no obvious difference in the syphilis occurrence was observed.

\section{DISCUSSION}

Cases of asymptomatic syphilis obtained in present study $(0.85 \%)$ could be at any one of the stages, primary or secondary or latent stage. If the syphilitic cases are not screened and treated, one third of them may proceed to the tertiary stage in the long run. ${ }^{5}$ In young male patients attending STD clinic in Calcutta India, the country with similar cultural, socio-economic, educational status, $16.6 \%$ seroprevalence has been reported which was also a case finding study. ${ }^{6}$

In present study, out of 25 RPR positive cases 22 were TPHA positive, three TPHA negative cases when tested after six months there was no increase in titre and remained negative in TPHA test. Hence, these three cases were considered as biological false positives (BFP). The BFP (non-treponemal cardiolipin response) has been reported to be $0.3-0.9 \% .^{5}$ However, the positivity also depends upon the specificity of test kit used.

Though 1-2\% false negative cases are report due to prozone phenomenon in secondary syphilis and it is recommended to dilute the serum 1:2 for RPR test in seronegative pregnant women in high prevalence area. ${ }^{8,9}$ In present study, serum was not diluted due to high cost and labor required for detecting possible
$1-2 \%$ false negative results. However, any doubtful results were repeated in 1:2 dilutions. Furthermore, Nepal is not a high prevalence area for syphilis and it is not worth taking risk of missing those cases which were positive in RPR and TPHA test in undiluted serum but negative in RPR test in 1:2 diluted serum.

The variation in the occurrence of syphilis in particular age group observed in this study could be due to the marital status, sexual behavior of people, migration from rural to urban areas, alcoholism, broken homes etc. Similarly the different pattern of occurrence of syphilis in different regions could be due to behavior of cluster of people with similar socio-economic condition, sexual behavior, etc. All the cases of syphilis identified in this study were treated by the registered practitioner to whom the author is indebted.

\section{CONCLUSION}

If the Cases of asymptomatic syphilis obtained in present study were not screened and treated, one third of them could proceed to the tertiary stage in the long run. Furthermore, morbidity of most STD in male is greater than in women, the individual with lowest socio-economic condition have the highest morbidity rate. Since the infection occurs only by sexual route, the poor young male with multiple sex partners and visiting prostitutes should be educated, screened and treated especially in developing countries. Such an step will not only decrease the spread of the infection to the partners it will also check the infected person from proceeding to tertiary syphilis with active infection which is observed in one third of the cases in latent stage infection.

\section{REFERENCES}

1. Robertson DHH, McMillan A, Young H. Clinical practice in sexually transmitted diseases. 2nd ed. Edinburgh: Churchill Livingstone; 1989. p. 108-17.

2. Gjestland T. The Oslo study of untreated syphilis - An epidemiological investigation of the natural course of untreated syphilis based on a study of the Boeck Bruusgard material. Acta derm Venereol 1955;35(Suppl 34):363-8.
3. Robertson DHH, McMillan A, Young H, Clinical practice in sexually transmissible diseases. 2nd ed. Edinburgh: Churchill Livingstone; 1989. p. 118-35.

4. Kumar V, Cotran RS, Robbins SLM. Basic pathology. India: Prism Books; 1992. p. 589-606.

5. Young H. Syphilis: new diagnostic directions. Int J STD AIDS 1992; 3(6):391-413. 
Shrestha. Screening of Syphilis in Abroad Job Seeking Healthy Males

6. Mitra K, Roy AK, Datta PK, Neogi DK. Seroprevalence of concomittant HIV and syphilitic infections among the STD clinic attenders in Calcutta. Indian J Dermatol 2000;45(4):182-5.

7. Park JE, Park K. Park's textbook of preventive and social medicine. Jabalpur (India): Banarsidas Bhanot; 1991. p. 225-6.

8. Young H, McMillan A. Editors, Immunological diagnosis of sexually transmitted diseases. New York: Marcel Dekker; 1988. p. 249-74.

9. Berkowitz K, Baxi L, Fox HE. False-negative syphilis screening: The prozone phenomenon, nonimmune hydrops and diagnosis of syphilis during pregnancy. Am J Obstet Gynecol 1990;163(3):975-7. 